\title{
LICENCIATURA INTERDISCIPLINAR EM ESTUDOS AFRICANOS E AFRO-BRASILEIROS: UMA GRADUAÇÃO PIONEIRA NO BRASIL
}

\author{
Cidinalva Silva Câmara Neris ${ }^{1}$ \\ KÁtia Regis ${ }^{2}$ \\ Pollyanna Gouveia Mendonça Muniz \\ Tatiane da Silva Sales ${ }^{4}$
}

\begin{abstract}
RESUMO: A Lei no 10.639/2003 tornou obrigatório o ensino da história e da cultura afro-brasileira e africana no Brasil. Nesse contexto, para que a temática integre as práticas curriculares de maneira efetiva, é imprescindível a descolonização dos currículos marcadamente eurocêntricos. Neste artigo, objetivamos refletir sobre como a Licenciatura em Estudos Africanos e Afro-Brasileiros (Liesafro), iniciativa pioneira no Brasil, implantada em 2015 na Universidade Federal do Maranhão (UFMA), realiza a formação de professores/as em interação com países africanos como Cabo Verde e Moçambique, numa perspectiva Sul-Sul de diálogos entre conhecimentos e práticas e em intercâmbio com as instituições da educação básica. Utilizamos como referencial teórico-metodológico autores/as como Quijano (2007, 2009), Walsh $(2010,2017)$ e Gomes (2017). Concluímos que a Liesafro/ UFMA integra o ensino da história e da cultura afro-brasileira e africana de modo estrutural em suas atividades de ensino, pesquisa e extensão e que promove a formação de professores/as em uma perspectiva emancipatória e antirracista.

Palavras-chave: Lei no 10.639/2003. Formação de professores/as. Ensino da História e da Cultura Afro-Brasileira e Africana. Liesafro/UFMA.
\end{abstract}

\section{INTERDISCIPLINARY DEGREE IN AFRICAN AND AFRO-BRAZILIAN STUDIES: A PIONEERING DEGREE IN BRAZIL}

ABSTRACT: The Law no. 10,639/2003 made the teaching of Afro-Brazilian and African history and culture mandatory in Brazil. In this context, in order to the theme integrates curricular practices effectively, it is essential to decolonize the markedly Eurocentric curriculum. In this article, we aimed to reflect on how the African and Afro-Brazilian Studies Degree (LIESAFRO), a pioneering initiative in Brazil implanted in 2015 at the Universidade Federal do Maranhão (UFMA), conducts teacher training in interaction with African countries such as Cape Verde

\footnotetext{
1.Universidade Federal do Maranhão - São Luís (MA), Brasil. E-mail: cidinalva.camara@ufma.br

2.Universidade Federal do Maranhão - São Luís (MA), Brasil. E-mail: katia_educ@yahoo.com.br

3.Universidade Federal do Maranhão - São Luís (MA), Brasil. E-mail: pgm.muniz@ufma.br

4.Universidade Federal do Maranhão - São Luís (MA), Brasil. E-mail: tatiane.sales@ufma.br

Editor de Seção: Salomão Barros Ximenes

Editores convidados: Nilma Lino Gomes, José Eustáquio Brito e Paulo Vinicius Baptista da Silva
} 
and Mozambique, in a South-South perspective of dialogue between knowledge and practices and in exchange with basic education institutions. We used as theoretical-methodological framework authors such as Quijano (2007, 2009), Walsh $(2010,2017)$ and Gomes (2017). We concluded that the LIESAFRO/UFMA integrates the Afro-Brazilian and African history and culture in a structural way in its teaching, research, and extension activities and carries out teacher training from an emancipatory and anti-racist perspective.

Keywords: Law no. 10,639/2003. Teacher training. Teaching of Afro-Brazilian and African History and Culture. LIESAFRO/UFMA.

\section{LICENCIATURA INTERDISCIPLINARIA EN ESTUDIOS AFRICANOS Y AFROBRASILEÑOS: UNA GRADUACIÓN PIONERA EN BRASIL}

RESUMEN: La Ley n. 10.639/2003 hizo obligatoria la enseñanza de la historia y cultura afrobrasileña y africana en Brasil. En ese contexto, para que la temática integre eficazmente las prácticas curriculares, es fundamental descolonizar los currículos marcadamente eurocéntricos. En este artículo, pretendemos reflexionar sobre de que manera la Licenciatura en Estudios Africanos y Afrobrasileños (LIESAFRO), iniciativa pionera en Brasil, implantada en 2015 en la Universidade Federal do Maranhão (UFMA), capacita a docentes en interacción con países africanos, como Cabo Verde y Mozambique, en una perspectiva Sur-Sur de diálogo entre conocimientos y prácticas y en intercambio con instituciones de educación básica. Utilizamos como referencial teórico-metodológico autores como Quijano (2007, 2009), Walsh $(2010,2017)$ y Gomes (2017). Concluimos que LIESAFRO/ UFMA integra la enseñanza de la historia y cultura afrobrasileña y africana de manera estructural en sus actividades de docencia, investigación y extensión y que realiza la formación docente desde una perspectiva emancipadora y antirracista.

Palabras-clave: Ley n. 10.639/2003. Formación de profesores. Enseñanza de la historia y la cultura afrobrasileña y africana. LIESAFRO/UFMA.

\section{Introdução}

A

Lei $\mathrm{n}^{\circ} 10.639 / 2003,{ }^{1}$ que tornou obrigatório o ensino da história e da cultura afro-brasileira e africana, configura-se como uma política de ação afirmativa. Como resultado das lutas do movimento negro brasileiro, ${ }^{2}$ é importante destacar o avanço na legislação sobre o tema: as Diretrizes Curriculares Nacionais para a Educação das Relações Étnico-Raciais e para o Ensino de História e Cultura Afro-Brasileira e Africana (Brasil, 2004), o Plano Nacional de Implementação das Diretrizes Curriculares Nacionais para a Educação das Relações Étnico-Raciais e para o Ensino de História e Cultura Afro-Brasileira e Africana (Brasil, 2009) e as Diretrizes Curriculares Nacionais para a Educação Escolar Quilombola (Brasil, 2012).

Ao situar na discussão curricular a obrigatoriedade do ensino da história e da cultura afro-brasileira e africana, a referida legislação oferece subsídios para o questionamento estrutural dos currículos das instituições educacionais, o que implica necessariamente a descolonização dos currículos vigentes. Conforme Sacristán $(1998,2013)$, o sistema educativo serve a determinados interesses concretos que se expressam por meio dos currículos, que não são neutros. O currículo é uma seleção configurada historicamente e 
relacionada ao contexto cultural, político, social, econômico e escolar. "Se o currículo, evidentemente, é algo que se constrói, seus conteúdos e suas formas últimas não podem ser indiferentes aos contextos nos quais se configura" (Sacristán, 1998, p. 21).

Com base nesse entendimento, os currículos não transmitem apenas o conhecimento acumulado pela humanidade; eles são parciais e predominantemente eurocêntricos. Segundo García (2018, p. 59), quando o eurocentrismo emerge como eixo político-ideológico hegemônico de dominação, o faz partindo do desprezo pelos "outros" povos do mundo, com objetivos totalmente econômicos e por meio da desqualificação, utilizando argumentos religiosos, intelectuais e biológicos: "Esa filosofía del desprecio se convirtió en 'eurocentrismo' y de ahí pasó al 'universalismo'. Surge así lo 'clásico' eurocéntrico como resultado del geo-euro-narcisismo. En fin, el mundo comenzó girar alrededor de la hegemonía eurocéntrica occidental" (García, 2018, p. 59).

Para o processo de descolonização dos currículos ${ }^{3}$, é indispensável que ocorra a discussão sobre outras concepções epistemológicas para além das eurocentradas, que permitam diferentes modos de aprender/ reaprender e que possibilitem a construção de práticas curriculares numa perspectiva intercultural crítica. De acordo com Walsh (2010), a interculturalidade crítica - enquanto prática política - engendra um percurso que não se limita às esferas políticas, sociais nem culturais; também está relacionada com o conhecimento, o ser e a própria vida. Preocupa-se com a exclusão ontológica e epistêmico-cognitiva, com a negação e subalternização de grupos e sujeitos racializados, pelas práticas - de desumanização e subordinação do conhecimento - que privilegiam uns sobre os outros, naturalizando a diferença e ocultando as desigualdades, que são estruturadas e mantidas. Assim, interculturalidade crítica e decolonialidade são projetos, processos e lutas - políticas, sociais, epistêmicas e éticas - que se articulam conceitual e pedagogicamente.

Nesse processo, as instituições de ensino superior (IES) estão sendo questionadas para realizarem mudanças emancipatórias para a descolonização de suas práticas curriculares - o que não é simples, pois implica a alteração do modo como historicamente os currículos foram estruturados. Nesse contexto de disputas epistemológicas em relação ao que é considerado legítimo a ser ensinado, surgiu o curso de Licenciatura Interdisciplinar em Estudos Africanos e Afro-Brasileiros (Liesafro), iniciativa pioneira implementada pela Universidade Federal do Maranhão (UFMA). Criado pela Resolução no 224, do Conselho Universitário (Consun), de 24 de fevereiro de 2015, teve início no dia 5 de maio de 2015, com a aula inaugural proferida pela ministra da Secretaria de Políticas de Promoção da Igualdade Racial professora doutora Nilma Lino Gomes.

No presente artigo, pretendemos refletir sobre como a Liesafro/UFMA integra, de modo estrutural, a história e a cultura afro-brasileira e africana em suas atividades de ensino, pesquisa e extensão destacando aspectos como: o projeto político-pedagógico (PPP) do curso; a interação com instituições da educação básica e com países do continente africano, como Cabo Verde e Moçambique; as ações do Núcleo Interdisciplinar de Estudos Africanos e Afro-Brasileiros (Niesafro); e a Kwanissa: Revista de Estudos Africanos e Afro-Brasileiros, vinculada ao curso e o principal instrumento de divulgação de trabalhos acadêmicos realizados ali.

\section{Licenciatura Interdisciplinar em Estudos Africanos e Afro-Brasileiros: Uma Graduação Pioneira no Brasil}

O racismo estrutural ${ }^{4}$ manifesta-se de diferentes formas e em diversos espaços, especialmente nas instituições de ensino de educação básica e nas universidades, espaços racializados nos quais a presença 
da população negra é limitada e suas falas silenciadas. A Liesafro vem assumindo o desafio de promover a produção e a socialização de conhecimento emancipatório desde sua criação, agindo para romper com esse silenciamento, fazendo ecoar saberes e epistemologias, por meio das vozes e das letras, assim como faz Anzaldúa (2000, p. 232):

Escrevo para registrar o que os outros apagam quando falo, para reescrever as histórias mal escritas sobre mim, sobre você [...] escreverei sobre o não dito, sem me importar com o suspiro de ultraje do censor e da audiência. Finalmente, escrevo porque tenho medo de escrever, mas tenho um medo maior de não escrever.

Para romper com o epistemicídio ${ }^{5}$ que marca a história da população negra em nosso país e o não reconhecimento da diversidade de saberes própria de nossa sociedade, é necessário que haja investimento na formação do corpo docente que atua na educação básica. Mas temos visto que apenas a formação continuada não surte o efeito suficiente para colocar em prática a educação das relações étnico-raciais (ERER), pois nossa atuação na educação básica tem confirmado o que Santos (2005, p. 89) aponta: "A escola por sua vez, colabora com a manutenção e continuidade do racismo, dado o seu silenciamento sobre as questões raciais e as situações de discriminação que marcam as relações raciais no contexto escolar".

O curso de Liesafro surgiu como uma tentativa de romper essa realidade, já que objetiva formar profissionais para a docência nos anos finais do ensino fundamental na área das ciências humanas (história, geografia, filosofia e sociologia), no ensino médio na área de história e para atuação nas secretarias municipais e estaduais de Educação, para a implementação da Lei no 10.639/2003 (UFMA, 2017b). A fim de que ocorra um processo formativo em consonância com as Diretrizes Curriculares Nacionais para a Educação das Relações Étnico-Raciais e para o Ensino de História e Cultura AfroBrasileira e Africana (Brasil, 2004), o ensino ofertado nessa licenciatura atende à formação docente para a educação básica em caráter interdisciplinar, tendo como princípios a consciência política e histórica da diversidade, o fortalecimento das identidades e de direitos e ações educativas de combate ao racismo e às discriminações.

Nessa ótica, a Liesafro, em suas atividades de ensino, pesquisa e extensão, suscita permanentemente o questionamento das concepções que validam somente a perspectiva eurocêntrica para a produção de conhecimento; discute sobre como a educação escolar hegemônica contribui para a permanência das diferentes formas de desigualdade e, ao mesmo tempo, é um território de possibilidades de desconstrução e de resistência; questiona o sistema político, econômico, cultural e social dominante e o constante processo de desumanização da população negra por meio da negação dos seus direitos e das violências física e simbólica; e indaga o racismo estrutural e a colonialidade ${ }^{6}$. De acordo com Quijano (2009, p. 73), a colonialidade é um dos elementos estruturantes e específicos do padrão mundial do poder capitalista, fundado na "imposição de uma classificação racial/étnica da população do mundo como pedra angular do referido padrão de poder e opera em cada um dos planos, meios e dimensões, materiais e subjectivos, da existência social quotidiana e da escala societal" (Quijano, 2009, p. 73).

Para tanto, na Liesafro há a compreensão de que para a história e a cultura afro-brasileira e africana serem abordadas com a seriedade, a rigorosidade e a complexidade necessárias, é imprescindível que a temática integre todas as suas atividades de ensino, pesquisa e extensão e que seja estrutural em seu PPP, o que pode ser evidenciado pela estrutura curricular do curso, explicitada na Quadro 1. 
Quadro 1. Estrutura curricular da Licenciatura Interdisciplinar em Estudos Africanos e Afro-Brasileiros: sequência esperada

\begin{tabular}{|c|c|}
\hline $1^{\circ}$ semestre & $2^{\circ}$ semestre \\
\hline Currículo & Didática \\
\hline Teoria da História & $\begin{array}{l}\text { África I: Historiografia, Sociedades } \\
\text { e Culturas da Antiguidade }\end{array}$ \\
\hline Filosofia e Diversidade & Política e Organização da Educação Brasileira \\
\hline Leitura e Produção Textual & Literatura Africana e Afro-Brasileira I \\
\hline Psicologia da Educação & Sociologia Geral \\
\hline $3^{\circ}$ semestre & $4^{\circ}$ semestre \\
\hline Fundamentos Sociológicos e Filosóficos da Educação & História da Educação \\
\hline África II: Estados e Sociedades do Século VII ao XVI & Cultura e Globalização \\
\hline Epistemologias do Sul & Etnofilosofia e Filosofia Africana \\
\hline Geografia Geral & $\begin{array}{l}\text { África III: Colonialismo, Independência } \\
\text { e Formação da África Contemporânea }\end{array}$ \\
\hline Antropologia e Cultura & Literatura Africana e Afro-Brasileira II \\
\hline $5^{\circ}$ semestre & $6^{\circ}$ semestre \\
\hline Sociologia Africana & Educação das Relações Étnico-Raciais I \\
\hline $\begin{array}{l}\text { História Pré-Colonial e Colonial do Brasil e do } \\
\text { Maranhão }\end{array}$ & História e Cultura Afro-Brasileira e Indígena \\
\hline $\begin{array}{c}\text { Geografia da África I: População, Cidades e } \\
\text { Geoeconomia }\end{array}$ & A Música Negra nas Américas no Século XX \\
\hline Linguística Afro-Brasileira & $\begin{array}{l}\text { Movimentos Sociais e Relações } \\
\text { Étnico-Raciais na América Latina }\end{array}$ \\
\hline História da Europa & História do Brasil e do Maranhão no Império \\
\hline $7^{\circ}$ semestre & $8^{\circ}$ semestre \\
\hline Educação das Relações Étnico-Raciais II & Educação, Gênero e Sexualidade \\
\hline História das Américas & Língua Brasileira de Sinais (Libras) \\
\hline História do Brasil e do Maranhão na República & $\begin{array}{c}\text { Geografia da África II: Recursos, Riscos e Conflitos } \\
\text { Socioambientais }\end{array}$ \\
\hline Educação Escolar Quilombola & Educação em Direitos Humanos \\
\hline Oriente Médio, Ásia e Oceania: sociedades e povos & Metodologia do Ensino de História \\
\hline
\end{tabular}

Fonte: Projeto Político-Pedagógico do Curso de Licenciatura Interdisciplinar em Estudos Africanos e Afro-Brasileiros (UFMA, 2017a).

À guisa de exemplo, na área de história, a Liesafro elaborou uma estrutura curricular que atendesse melhor à história e à cultura do continente africano. Para tanto, conta com os componentes curriculares denominados de África I, II e III, além de inserir essas temáticas em todos os demais componentes da área de história do curso. Isso não significa focar numa história afrocêntrica, já que o currículo não descuida das 
experiências específicas da história no Brasil e no Maranhão - contemplada em mais três componentes -, além da história da América, do Oriente Médio, da Ásia e da Oceania - estas últimas costumam figurar apenas como componentes não obrigatórios nos cursos de graduação no país.

Faz-se importante enfatizar que o componente curricular denominado de História da Europa, por exemplo, é construído epistemologicamente como mais uma ferramenta para descolonizar o currículo, pois, como menciona o historiador francês Gruzinski (2003, p. 321), os/as especialistas no que se convencionou chamar de história mundial "tenderam a elaborar sua visão do mundo a partir da Europa ocidental ou de problemáticas que provinham da história deste continente". Isso quer dizer que marcos temporais definidos e aceitos em consenso para demarcar a história do mundo precisam ser matizados, porque em sua maioria são marcos temporais da Europa Ocidental. Daí ser urgente a necessidade de se fazer frente "ao conservadorismo europeu e francês" e criticar "o eurocentrismo da história e das ciências sociais em geral” (Gruzinski, 2003, p. 322).

Ainda hoje nos cursos regulares de História existentes no Brasil - aqui tomados como exemplo as licenciaturas -, a história da Europa aparece como central na história do mundo e abarca a maior carga horária desses cursos. Coelho e Coelho (2018, p. 15) destacam:

Salta aos olhos o volume do espaço europeu nos currículos de formação. A Europa é espaço absoluto de atenção em disciplinas voltadas para a compreensão de processos que nela ocorreram, como é o caso de História Antiga, História Medieval, História Moderna e História Contemporânea. Em seguida, a mesma Europa aparece como epicentro dos eventos que regulam processos em outras partes do globo - situação frequente em disciplinas voltadas para o trato com os processos de colonização da América (seja tratando do continente, nas disciplinas regularmente denominadas de História da América I, seja nas disciplinas voltadas para a abordagem da História do Brasil, identificadas, via de regra pelo numeral romano I), mas presentes também em disciplinas relativas à História da África, História Indígena, História da América ou do Brasil independentes e nas disciplinas de natureza teórico-metodológica. Nestas últimas, é meramente incidental a referência às perspectivas decoloniais que buscam estabelecer uma crítica à orientação eurocêntrica.

Assim, a proposta curricular da Liesafro parte em sentido oposto ao eurocentrismo do currículo em História, ou, como menciona Gruzinski (2001), enfrenta a ideia consolidada nos currículos de que a história do continente europeu é a de $h$ maiúsculo, enquanto o estudo do passado de outras partes do mundo é apenas uma história com $h$ minúsculo.

Outro destaque da proposta curricular decolonial efetivada na Liesafro se dá por meio da disciplina, de caráter obrigatório, Educação, Gênero e Sexualidade, que discute de forma abrangente as temáticas educação, gênero e sexualidade, numa perspectiva de construção de propostas e de estímulo a novas ações no processo de educação sexual emancipatória, antissexista e não discriminatória em organizações educativas formais e não formais. Tal abordagem curricular é única no componente obrigatório da UFMA e uma das poucas iniciativas no Brasil.

É importante também destacar o pioneirismo e a relevância para tratar a decolonialidade dos componentes curriculares Epistemologias do Sul, Filosofia Africana e Sociologia Africana. Pelo primeiro, busca-se, como diz Santos (1995, p. 508), "aprender que existe o Sul; aprender a ir para o Sul; aprender a partir do Sul e com o Sul”. Assim, o Sul é metaforicamente "um campo de desafios epistêmicos que procuram reparar os danos e impactos historicamente causados pelo capitalismo na sua relação colonial com o mundo" (Santos e Meneses, 2009, p. 12). Combatendo o epistemicídio ou a invisibilização dos conhecimentos locais, a 
ideia desse componente curricular é continuar com a reflexão e a problematização do pensamento ocidental. É compreender, como afirma Quijano (2009), que o colonialismo continuou sob a forma de colonialidade de ser e saber. ${ }^{7}$

No que diz respeito à Etnofilosofia e Filosofia Africana, a proposta é igualmente inovadora. Se há muito perdura a percepção de que a filosofia é produto quase que exclusivo da Europa Ocidental, esse componente curricular coloca em destaque a variedade do pensamento filosófico existente no pensamento africano. A proposta é conduzir os/as discentes à interpretação de autores/as africanos/as e da diáspora, como Aimé Césaire, Cheikh Anta Diop, Frantz Fanon, Kwame A. Appiah, Leópold Senghor, entre outros. A ênfase ao pensamento válido como aquele produzido no continente europeu é solapada por uma proposta que questiona o eurocentrismo também na filosofia.

Por fim, o componente curricular Sociologia Africana vem sendo trabalhado nesse mesmo sentido, buscando promover a problematização a respeito da homogeneização do conhecimento produzido no eixo articulador Europa/Estados Unidos. Para isso, é necessário assumirmos que, nas sociedades formadas por intermédio da colonização moderna, o pensamento social nasceu em meio ao processo de universalização do conhecimento produzido, inicialmente, na Europa e, após a Segunda Guerra Mundial, também nos Estados Unidos. A consequência direta dessa universalização é o que podemos chamar de dominação de saberes, que, por sua vez, resulta em outros desdobramentos, como, por exemplo a ideia de que só se produz conhecimento na parte Norte do planeta; a imposição das agendas de pesquisas realizadas nesse espaço; a ausência das mulheres nos cânones intelectuais, seja a nível local, seja a nível global; e a divisão do trabalho intelectual, oferecendo aos/às intelectuais do Sul a posição subalterna de produtores de dados e aplicadores dos modelos e aos do Norte a de dominantes, de produtores de teorias/modelos de análises.

Conforme Alatas (2010), essa universalização do conhecimento está inserida num debate sobre a dependência acadêmica, no que considera como "imperialismo intelectual", fenômeno que se combina com as dominações política e econômica, amplamente trabalhadas pela literatura pós-colonial. Logo, o autor destaca:

Pouco podemos fazer a respeito das dimensões estruturais e materiais desta dependência, pois não estamos no comando das instituições e do Estado. Contudo, há muito a ser feito nos níveis intelectual e teórico. Nestes níveis, práticas culturais e tradições de conhecimento não-ocidentais podem ser consideradas como fontes potenciais para conceitos e teorias, o que iria diminuir a dependência acadêmica diante dos poderes globais das ciências sociais (Alatas, 2010, p. 225-226).

Esse debate é importante para a formação dos/as docentes que vão atuar na educação básica, na medida em que mobiliza argumentos, sujeitos, experiências e processos históricos locais e regionais nos quais a comunidade escolar está inserida, interconectando-as ao global. Ao mesmo tempo, ele critica os modelos, métodos ou narrativas dominantes nas ciências sociais. Mas, além disso, a formação ofertada pela Liesafro, por ser interdisciplinar e envolver seus/suas estudantes com a educação básica desde o início do curso, tem o potencial ainda maior de problematizar esse referencial de ciência baseado na divisão de saberes na qual os/as alunos/as não são detentores nem produtores de saber.

Nesse sentido, a disciplina Sociologia Africana busca inserir os/as estudantes no debate que se estabeleceu nas sociologias mediante a imposição da concepção moderna sobre a constituição dos saberes nas ciências sociais, como podemos ler nos vários autores/as trabalhados/as na disciplina e que levantam a bandeira da "descolonização e a abertura das Ciências Sociais como um processo de repensar o universalismo, a partir de experiências locais e específicas” (Rosa, 2015, p. 315), como Lander (2005), Santos e Meneses (2009), Alatas ((2010), entre outros/as. 
Por fim, uma vez que a problemática da hegemonia euronorte-americana nas ciências sociais é uma questão de dominação epistêmica, ou seja, que os modos de ver e interpretar o mundo repassado na educação fazem parte de um conjunto mais amplo de dominações, é salutar que nossa juventude compreenda que o conhecimento com o qual tem contato está inserido em um quadro mais geral que movimenta as relações sociais nas quais se envolvem. Como afirma Roulleau-Berger $(2021$, p. 1): "For several centuries, the history of the West has merged with the history of the world. The global economy of knowledge is structured around epistemic inequalities, hegemonies, and dominations".

Questionar essa estrutura é uma das propostas da Liesafro, de maneira especial por considerarmos que ela é um fator de grande relevância na manutenção das múltiplas desigualdades, do racismo e da exclusão que marcam a existência da população negra brasileira e o silenciamento de seus saberes, colocando essa população historicamente numa posição de subalternidade.

\section{A Liesafro no Chão da Escola e em Diálogo com o Continente Africano: Experiências Práticas da Formação Docente para o Ensino da História e da Cultura Afro-Brasileira e Africana}

Apesar de serem aqui citados exemplos específicos de alguns componentes curriculares, a Liesafro realiza a formação inicial numa perspectiva emancipatória e antirracista em todas as áreas que abrange. A licenciatura também está em permanente interação com as instituições educacionais da educação básica, o que pode ser evidenciado, por exemplo, por meio da Prática de Ensino como Componente Curricular (PECC), que possui carga horária de 405 horas e integra disciplinas pedagógicas e disciplinas de cada área de conhecimento do curso. De acordo com o PPP do curso (UFMA, 2017a), seu objetivo é estabelecer a articulação reflexiva entre a teoria e a prática, por intermédio da análise da realidade escolar mediante diferentes aspectos, tais como: o currículo; o PPP; o planejamento escolar; a didática acerca do desenvolvimento de conteúdos/ temas pelos/as docentes; a observação da interação entre a escola e a comunidade; e a relação professor/a e estudante no processo de avaliação.

Outros modos pelos quais se estrutura a permanente interação com as escolas são percebidos em programas de iniciação à docência: Programa de Residência Pedagógica e Programa Institucional de Bolsas de Iniciação à Docência (Pibid).

O subprojeto do Pibid intitulado Ciências humanas, interdisciplinaridade e estudos africanos e afro-brasileiros no enfrentamento ao perigo de uma história única está em atividade desde 2018 e foi elaborado seguindo as orientações utilizadas nos componentes curriculares do curso de graduação, ou seja, fundamenta-se na preocupação de que a formação dos/as docentes e, consequentemente, a oferta do ensino em ciências humanas ainda estejam baseadas numa herança derivada do colonialismo cultural, eurocentrada e que minimize ou até mesmo exclua qualquer referência à história afro-asiática e indígena. Assim, ao pensar no enfrentamento de uma história única (Adichie, 2019), o projeto busca superar a visão de uma história etnocêntrica que ainda invisibiliza sociedades e sujeitos. O que se pretende é a melhoria e o aprofundamento da formação docente e também familiarizar os/as discentes do curso com a realidade do ensino de história na educação básica. Trata-se de um espaço de intercâmbio dinâmico e da construção de experiências políticopedagógicas mais inovadoras.

O projeto é desenvolvido no Colégio Aplicação (Colun) da UFMA e atualmente aborda como temática central as relações étnico-raciais, o gênero e a diversidade: possibilidades e desafios no ensino de história, compreendida no campo dos estudos culturais, pois privilegia categorias que questionam as 
atitudes de normalização e problematiza como a identidade hegemônica do homem ocidental, europeu (ou europeizado), branco, cisgênero e heterossexual cria condições de consolidar-se enquanto desejável, única, normal e existente no ambiente escolar. O programa possui oito alunos/as bolsistas e dois voluntários/ as e, por meio das atividades de acompanhamento e intervenção, atua nos ensinos fundamental e médio, contemplando cerca de 160 alunos/as de forma direta, sendo um espaço de promoção de vivências e práticas docentes em suas muitas realidades.

Destacamos que o Pibid, por intermédio de bolsas de iniciação à docência aos/às alunos/as de licenciaturas presenciais, fomenta o vínculo entre futuros/as profissionais da educação, os desafios da sala de aula, as possibilidades de aprendizagem ativa e a superação de tais desafios.

Desta feita, com base nos desafios que ora se apresentam e somados aos que historicamente já se impõem, temos como reflexão em que medida as práticas e propostas realizadas pelo Pibid (Liesafro/ UFMA) assumem caráter decolonial. Atentamo-nos em dizer que se trata de um desafio constante, da possibilidade de releituras, de ampliação de visões e busca por saberes que, notadamente, encaminham para novas práticas pedagógicas. Pedagogias que perturbam e transformam, que se esforçam por transgredir a negação ontológico-existencial, epistêmica e cosmológica/espiritual de que resultou a colonialidade e que aponta para uma nova humanidade. Pedagogias que não são pensadas externamente às histórias nem às realidades dos povos e das gentes, mas que buscam lutas de conscientização, afirmação e desalienação, como destaca Walsh (2017, p. 29): "Las pedagogías, en este sentido, son las prácticas, estrategias y metodologías que se entretejen con y se construyen tanto en la resistencia y la oposición, como en la insurgencia, el cimarronaje, la afirmación, la re-existencia y la re-humanización".

Desse modo, a pedagogia decolonial ${ }^{8}$ é uma prática ancorada não apenas na resistência, mas em construção de vida melhor para todos/as, levando em consideração condições e propostas para outros pensamentos, levantamento de propostas pedagógicas, práticas como pedagogias que questionem e desafiem a voz única da modernidade ocidental e do poder colonial nela presente, pedagogias que incitam possibilidades de estar, ser, sentir, existir, fazer, pensar, olhar, escutar e saber de outro modo, voltadas para um caráter horizontal e decolonial. Não consistem em um pedagógico limitado apenas ao campo escolarizado de saber, mas inserem-se nos cenários sociais, políticos e epistêmicos.

Destarte, entendemos que, ao propor leituras outras com base no livro didático, produção de outros materiais pedagógicos, diálogos haja vista as realidades de discentes e docentes, observação do chão da escola e do seu projeto pedagógico, com saberes que foram historicamente ignorados e silenciados, o Pibid (Liesafro) na UFMA tem assumido esses desafios de romper com a lógica de saberes únicos e de promover um ensino/aprendizagem reflexivo, ativo tanto para discentes da licenciatura e da escola-campo quanto para os/as docentes envolvidos/as.

Nesse mesmo sentido, a residência pedagógica da Liesafro tem sido um frutífero espaço para a formação docente voltada para a aplicação da Lei $n^{\circ}$ 10.639/2003. Isso porque ela proporciona aos/as licenciandos/as vivências mais próximas da realidade concreta da educação básica brasileira. Essa aproximação tem como objetivo levá-los/as a compreender as dinâmicas, os contrastes, os desafios e as potencialidades que permeiam sua futura profissão, de colocar em prática uma educação de fato emancipatória e antirracista na qual o ensino da história e da cultura afro-brasileira e africana seja nuclear.

Criado pela Coordenação de Aperfeiçoamento de Pessoal de Nível Superior (Capes) no ano de 2018, o Programa de Residência Pedagógica faz parte da "Política Nacional de Formação de Professores", e, segundo seu Art. $1^{\circ}$, sua finalidade é: "Apoiar Instituições de Ensino Superior (IES) na implementação de projetos inovadores que estimulem a articulação entre teoria e prática nos cursos de licenciatura, conduzidos em parceria com as redes públicas de educação básica" (Brasil, 2018, p. 28). 
Como a residência pedagógica da Liesafro faz parte de uma proposta de formação integral do/a licenciando/a, nas duas edições até agora, os subprojetos foram estruturados de maneira a contemplar as normas de estágio curricular obrigatório. Isso significa que, apesar de a Capes ainda manter seu entendimento do ensino de maneira disciplinar e mesmo o nosso núcleo sendo o da área da história, as atividades desenvolvidas são interdisciplinares, assim como a Liesafro. Logo, o/a residente atua nas quatro disciplinas das ciências humanas de sua formação - História, Geografia, Sociologia e Filosofia -, acionando os saberes dessas disciplinas em todas as atividades realizadas nas duas etapas da educação básica - ensino fundamental maior e ensino médio. Acredita-se que essa forma de estruturação das atividades da residência pedagógica seja capaz de proporcionar uma formação mais completa aos/às licenciandos/as, oferecendo alternativas viáveis para a execução da Lei no 10.639/2003 para os/as professores/as das escolas-campo e experiências de aprendizagem mais próximas da realidade vivida pelos/as estudantes da educação básica e pelos/as próprios/ as residentes.

Na primeira edição do programa, que se deu entre os anos de 2018 e 2020, a Liesafro participou com o subprojeto intitulado Residência pedagógica: saberes e fazeres interdisciplinares na Licenciatura Interdisciplinar em Estudos Africanos e Afro-Brasileiros. Os principais objetivos desse projeto foram: proporcionar aos/às residentes conhecimentos teóricos e práticos, possibilitando-lhes experiências capazes de auxiliá-los/as a desenvolver habilidades e competências necessárias à efetivação da ERER, conforme preconizado pelas Diretrizes Curriculares Nacionais para a Educação das Relações Étnico-Raciais e para o Ensino de História e Cultura Afro-Brasileira e Africana (Brasil, 2004); e desenvolver projetos de intervenção na temática étnicoracial de acordo com a Lei $n^{\circ} 10.639 / 03$ e a Lei $n^{\circ} 11.645 / 08$, que inter-relacionam universidade, escola e comunidade.

Essa primeira edição da residência pedagógica da Liesafro teve como campo três escolas públicas estaduais, localizadas em áreas periféricas e caracterizadas como de alto índice de vulnerabilidade social de São Luís (MA): o Centro de Ensino Antônio Ribeiro da Silva, no entorno da UFMA, no bairro do Sá Viana; o Centro de Ensino Estado do Pará, situado no bairro da Liberdade, que faz parte do núcleo central da cidade, área de antiga ocupação de migrantes do interior do estado; e o Centro de Ensino Integral Gonçalves Dias, em uma área de passagem do centro para outras regiões da cidade.

Trinta residentes - sendo 24 bolsistas e seis voluntários -, três preceptores ${ }^{9}$ e uma docente orientadora ${ }^{10}$ compuseram a equipe dessa primeira etapa da residência pedagógica, que, mesmo enfrentando grandes desafios, se empenhou grandemente na construção de estratégias a fim de colocar em prática o ensino oferecido na Liesafro, como, por exemplo, a realização de oficinas, palestras, curso sobre a utilização de história em quadrinhos no ensino da história, rodas de conversa e cinedebates, abordando as questõesalvo de nossa residência pedagógica, envolvendo toda a comunidade escolar das três escolas.

Nesse momento estamos desenvolvendo a segunda edição da residência pedagógica, que teve início em novembro de 2020 e vai até abril de 2022, com o título Licenciatura em Estudos Africanos e Afro-Brasileiros: formação de professores/as e justiça curricular. O projeto busca problematizar o currículo hegemônico, questionando o epistemicídio da população negra por intermédio do silenciamento de sua contribuição na construção da sociedade brasileira. Essa realidade está sendo percebida na prática por toda a equipe no cotidiano escolar. Muitas são as oportunidades nas quais os/as residentes notam a ausência dos saberes da comunidade na qual a escola está localizada, pela baixa representatividade de autores/as negros/as nos conteúdos trabalhados nas aulas, pelas práticas pedagógicas e concepções epistemológicas eurocentradas, pela folclorização da cultura afro-brasileira e africana, pela falta de questionamento da estrutura racista da sociedade brasileira, pela naturalização das relações étnico-raciais que excluem a população afro-brasileira e pela negação do racismo, observável nos conteúdos lecionados e que revelam a falta de interesse de nossa 
sociedade em superar o racismo estrutural, as múltiplas desigualdades e as exclusões que marcam a existência da população negra brasileira.

A realização da residência pedagógica nesse período tem sido um grande desafio. A pandemia de Covid-19 impôs a reestruturação de nossas atividades e levou-nos a refletir sobre a formação docente no contexto de mudanças e das incertezas sobre como será o exercício da docência desse momento em diante. $\mathrm{O}$ isolamento social e o consequente modelo de aulas remotas evidenciaram os problemas gerados pelas desigualdades que marcam nossa sociedade, especialmente a exclusão digital.

Destaca-se que, apesar dos dilemas, uma vez superadas as incertezas iniciais, se percebeu o quanto essas questões estão estreitamente ligadas à justiça curricular, tema central da residência pedagógica da Liesafro. Afinal, o ambiente escolar não está desconectado do que acontece fora dos seus muros, como muitas práticas educativas parecem considerar. Muito pelo contrário, esse contexto confirmou que a prática educativa não pode estar desconectada da realidade da comunidade escolar e que todos têm o papel de refletir e de buscar alternativas para que a escola possa cumprir suas funções.

Outro aspecto que estrutura a perspectiva epistemológica da Liesafro se relaciona ao seu processo de internacionalização em direção ao continente africano, pois se tem o entendimento de que as interações entre o Brasil e os diferentes países da África podem favorecer a fundamentação teórica necessária para que o que é ensinado sobre a história e cultura africana e afro-brasileira e africana não continue passando pelo crivo eurocêntrico, mas seja construído em discussões com o continente africano em toda a sua diversidade, suas lutas, seus desafios e suas potencialidades atuais.

Logo, o curso estabeleceu um termo de cooperação técnico-científica com a Secretaria de Estado da Educação do Maranhão (Seduc-MA), que viabilizou o trabalho de campo em Praia, Cabo Verde, entre os dias 21 de novembro e 7 de dezembro de 2018 de 50 integrantes (docentes, discentes, técnico administrativa e bolsistas) dos Estudos Africanos e Afro-Brasileiros. Durante a estadia em Cabo Verde, houve o I Colóquio Internacional Políticas Antirracistas no Mundo, organizado em parceria com a Universidade de Cabo Verde; visitas guiadas (Fundação Amílcar Cabral, Museu Histórico Nacional, Biblioteca Nacional, Presídio do Tarrafal, Forte de São Filipe e Cidade Velha); trocas culturais com a Associação Kobom; roda de conversa na Biblioteca Nha Balila; e reunião no Ministério da Educação de Cabo Verde. A contrapartida da Liesafro ao financiamento do trabalho de campo em Cabo Verde pela Seduc-MA foi a realização do curso de formação continuada Educação para as Relações Étnico-Raciais e para o Ensino da História e Cultura Africana e AfroBrasileira, que foi ofertado para 350 docentes da educação básica do estado do Maranhão entre os dias 18 e 22 de novembro de 2019.

$\mathrm{Na}$ continuidade do processo formativo pela Liesafro, que pretende aproximar o curso de universidades de diferentes países do continente africano e das IES brasileiras, foi desenvolvido por docentes, entre os dias 22 de abril e 20 de maio de 2019, trabalho de campo em Maputo, Moçambique, mediante a integração de ações de dois projetos de cooperação internacional financiados pela Fundação de Amparo à Pesquisa e ao Desenvolvimento Científico e Tecnológico do Maranhão (Fapema): o projeto de pesquisa intitulado O ensino de história e cultura africana no Brasil e em Moçambique: formação de professores/as em uma perspectiva intercultural; e a investigação Corredores de desenvolvimento no Brasil e em Moçambique: estudo acerca das transformações no mundo do trabalho e do acesso à terra a partir da instalação do corredor de Nacala (Moçambique) e Estrada de Ferro Carajás (Brasil)". Diversas atividades ocorreram ao longo da estadia em Maputo: reuniões técnicas entre pesquisadores/as moçambicanos/as e brasileiros/as; visitas a escolas; reuniões com integrantes do Instituto de Formação de Professores, do Instituto Nacional para o Desenvolvimento da Educação e do Observatório do Meio Rural; lançamentos de livros; e rodas de conversa com a Associação de Escritores Moçambicanos e com diferentes movimentos de mulheres moçambicanas. Também foi realizado o 
Seminário Estudos Africanos e Afro-Brasileiros: Perspectivas Interculturais Emancipatórias, organizado em parceria com o Centro de Estudos Moçambicanos e Etnociências, da Universidade Pedagógica de Maputo.

Os resultados frutíferos do trabalho de campo podem ser notados, por exemplo, pelo estabelecimento, em 2019, de novo termo de cooperação técnico-científica com a Seduc-MA, para promover a formação continuada de professores/as da educação básica do Maranhão, que vai viabilizar trabalho de campo em Moçambique de docentes e discentes da Liesafro ${ }^{11}$. Também se impulsionou a proposição de duas investigações de pós-doutorado: A inclusão do conhecimento local no currículo da África do Sul, de Moçambique, da Tanzânia e do Zimbabwe: fundamentos epistemológicos para o ensino da história e cultura africana e afro-brasileira a partir da ancestralidade africana (financiada pela Fapema) e Organização camponesa e a produção de alimentos em regiões de avanço da moderna agricultura em Moçambique e no Brasil.

Além disso, durante a estadia em Maputo foram muito estimulantes os diálogos entre as duas equipes de cooperação internacional. Dessas interlocuções, no decorrer do trabalho de campo foi proposta a criação do Niesafro, com o objetivo de articular pesquisas acerca dos estudos afro-brasileiros e africanos realizados pelos/as docentes de diferentes áreas do conhecimento da Liesafro.

\section{Niesafro e Kwanissa: Revista de Estudos Africanos e Afro-Brasileiros: Espaços de Produção e de Socialização de Conhecimento Antirracista e Emancipatório}

O Niesafro foi criado em 2019 como o primeiro núcleo de pesquisa ligado à Liesafro. Seus objetivos são ampliar, consolidar e socializar a produção de pesquisas em diversos âmbitos e, de forma especial, sobre a história e a cultura africana, afro-brasileira e afro-americana e a educação, além de contribuir para a construção de uma educação intercultural crítica e emancipatória. Nesse sentido, está composto de três linhas de pesquisa, que agregam professoras/es da Liesafro e de outros cursos e instituições: espaço, relações de poder e sociabilidades; interculturalidade, africanidades e educação; e linguagens e africanidades.

Os/as pesquisadores/as que compõem o núcleo vêm desenvolvendo importantes projetos de ensino, pesquisa e extensão, e o núcleo tem construído redes de relações acadêmicas com outras instituições brasileiras e internacionais e com o poder público. Durante o período da pandemia da Covid-19, o Niesafro, em parceria com a Liesafro, com o Núcleo de Estudos Afro-Brasileiros (NeabUFMA) e com o Núcleo de Estudos e Pesquisa sobre Educação das Relações Étnico-Raciais e de Gênero (Neperge-UFMA), ofereceu um curso de aperfeiçoamento de 180 horas com o objetivo de dialogar sobre as possibilidades da produção de conhecimento e do exercício de práticas libertadoras, democráticas e emancipatórias de educação, contribuindo assim para a formação continuada de professores/as e de lideranças dos movimentos sociais. Além disso, também participou do curso de formação a docentes da Seduc-MA realizado pela Liesafro, em contrapartida do trabalho de campo financiado pelo estado do Maranhão.

Além do objetivo já mencionado, o curso de formação Estudos Africanos e Afro-Brasileiros em Perspectiva: Produção de Conhecimento Interdisciplinar para uma Educação Emancipatória visava também traçar um quadro que nos permitisse compreender a demanda de formação e debates sobre as relações étnicoraciais entre o público para o qual ele foi pensado, bem como as áreas da atuação desses demandantes. Nesse sentido, a grande procura pelo curso, que levou ao preenchimento de todas as vagas logo nos primeiros minutos depois de iniciadas as inscrições, só confirmou o quanto o ensino dessas temáticas é deficiente em todo o país, como podemos perceber pela variedade de locais de origem dos/as cursistas, de todas as regiões e de muitas áreas do saber - ciências humanas, tecnológicas, sociais aplicadas e área médica. 
Diversas também eram as áreas de atuação dos/as cursistas. A maioria trabalhava na educação, da educação infantil ao ensino superior, em escolas urbanas, rurais e quilombolas, mas havia ainda aqueles que atuavam em organizações civis que defendem os direitos das mulheres e das crianças e na administração pública, como lideranças de comunidades quilombolas, para citar alguns. Essa diversidade do grupo de participantes evidencia que a escola formal não é o único espaço no qual se pode e se deve pôr em prática a educação antirracista. Esta precisa ser exercida em todos os espaços da sociedade, uma vez que o racismo está em todos os lugares. Demonstra também a importância de referenciais negros de pessoa, tempo e espaço na formação da identidade da população negra.

Salienta-se que o curso foi completamente gratuito e contou com a participação de profissionais com destacada atuação na área, oriundos de instituições brasileiras e de Guiné-Bissau. É importante mencionarmos esses aspectos para ressalvar as temáticas abordadas no decorrer dos três ciclos do curso:

- As contribuições do movimento negro para a democratização da educação;

- Quadrinhos de África, África de quadrinhos;

- Território e economia em comunidades camponesas no Brasil;

- Entre páginas e palcos: as percepções do feminino numa perspectiva atlântica entre o Maranhão e Cabo Verde;

- Educação antirracista 1 - ações afirmativas: cotas raciais e acesso ao ensino superior;

- Movimentos sociais e processos de educação para a cidadania;

- Moçambicanamente: viagens aos anos 70 e 80 nas quilhas de textos literários;

- Educação antirracista 2 - Lei 10.639/2003: educação antirracista e emancipatória;

- África e africanidades no contexto escolar e acadêmico;

- África pós-independência: utopias e realidades;

- Educação escolar quilombola;

- (Re)aprendendo gênero, raça e sexualidade na educação superior: desobediência epistêmica em debate.

Esses temas possibilitaram debates e reflexões a respeito dos desafios enfrentados para formar, nos mais diversos espaços, uma sociedade antirracista e democrática de fato. Do mesmo modo, essas abordagens tinham como objetivo promover o debate sobre a necessidade de sairmos do campo da denúncia das condições de existência da população negra em nosso país para a proposição de estratégias de superação do desrespeito quanto às formas de pensar, ser e estar do povo negro. Só para ilustrar esse argumento, citamos um depoimento de uma cursista no fórum de apresentação do curso. Nele podemos perceber uma mulher negra que ainda estava em processo de reconhecimento de sua identidade enquanto tal, mesmo já cursando o doutorado:

Chego ao curso com o desejo de viajar por uma estrada que me auxilie na minha constituição como pessoa, mulher negra, mas também me leve a um local em que possamos cada vez mais ser, constituir e construir pessoas e espaços que possibilitem a nossa emancipação enquanto povo. [...] A minha expectativa neste curso é poder construir um aprendizado que me auxilie na apresentação ética e política de caminhos cada vez mais justos e baseados no respeito à humanidade das pessoas, especialmente do nosso povo negro (S. M). 
A principal estratégia que a atuação da Liesafro põe em relevo é a produção de conhecimento que tome o continente africano e sua diáspora, especialmente na América Latina, como centro, conhecimento alicerçado em alternativas epistemológicas que questionem o modelo hegemônico de saber.

Nesse sentido, como forma de divulgar as produções realizadas no âmbito da Liesafro, bem como propiciar um espaço de discussão entre pesquisadores/as nacionais e internacionais que se articulam em torno da produção de conhecimento emancipatório acerca dos estudos africanos e afro-brasileiros, em 28 de março de 2018 surgiu a Kwanissa: Revista de Estudos Africanos e Afro-Brasileiros (ISSN 2595-1033), que é vinculada ao curso. Kwanissa significa no idioma sena, de Beira (Moçambique), "resista, aguente firme". Atualmente a revista possui nove números, com média de dois números por volume anuais, e objetiva somar-se às ações do curso, divulgar as pesquisas e os trabalhos desenvolvidos na licenciatura interdisciplinar (como resultados das experiências acumuladas, pesquisas realizadas e projetos desenvolvidos) e as interlocuções de trabalhos acadêmicos nacionais e internacionais que dialogam com as temáticas de diversas perspectivas das relações étnico-raciais e de estudos africanos e afro-brasileiros.

A revista recebe trabalhos em forma de fluxo contínuo, tem edições semestrais, possui comissão científica composta de docentes de várias universidades do país e hoje, com o nono número, já foi visitada desde o seu lançamento por mais de 93 mil pessoas de todos os continentes. Possui em seu portfólio 98 artigos, quatro relatos de experiência e três resenhas, contabilizando 147 autores/as e textos publicados em português, espanhol e inglês, que dialogam sobre as múltiplas realidades sociais, políticas, educacionais, entre outras temáticas. O periódico promove a dinâmica de pesquisas e experiências num processo de luta por uma educação antirracista, dialógica e decolonial, retomando visões de mundo, conteúdos e metodologias de que a ciência ocidental se apropriou e acumulou, em uma racionalidade cartesiana.

\section{Conclusão}

Por meio do postulado do colonialismo e da colonialidade, a produção dos saberes foi organizada e hierarquizada a fim de constituir um modelo universal de conhecimento considerado como o único válido, e no topo dessa hierarquia se consagrou o ideal vigente da modernidade europeia, promovendo a difusão de um Ocidente segmentado pelo capitalismo e pela ideia de uma linha evolutiva ancorada nas raças/etnias. Quijano (2007) usa o termo colonialidade do poder, saber e ser para expressar o quanto as formas de pensar, agir e existir foram invadidas com ações violentas da ocidentalização, destruindo imaginários, reprimindo os modos de produção de conhecimento, os saberes, o mundo simbólico e impondo novos.

Assim, a não humanização é uma das estratégias de controle e disciplinamento dos povos na perspectiva de produzir inexistências, corroborar com hierarquias e consagrar locais, seres e saberes já vistos como válidos. Daí a importância de produzir pensamentos outros, pensamentos de fronteiras e da luta contra a não existência, ou existência mediada. É nesse posicionamento que a Liesafro, situada em uma universidade pública, numa região, estado e país tidos enquanto periféricos, tem destacado campos de saberes historicamente desprezados como objetos de estudo, pesquisa e reflexão, promovendo saberes que visam à reconstrução do ser, poder e saber, impulsionando outros modos de existir por meio do pensamento crítico de fronteira e da perspectiva decolonial.

Portanto, decolonizar é visibilizar as lutas contra a colonialidade por intermédio das pessoas, das suas práticas sociais, epistêmicas e políticas. É também promover pesquisas e saberes, assim como divulgá-los e incentivá-los num processo de ensino-aprendizagem, no chão da escola, nas interlocuções com universidade africanas, nas leituras realizadas, nos objetivos das pesquisas financiadas, nos projetos de extensão desenvolvidos, em pesquisas, livros e artigos publicados, isto é, em todas as dinâmicas experimentadas na 
formação docente de ensino superior. A Liesafro promove fazeres e saberes de uma pedagogia decolonial baseada numa insurgência educativa propositiva e na construção de outras formas de pensamento, ação, cultura e condições de vida, mesmo levando em consideração todo o processo de disputa envolvido nos espaços políticos, conceituais, linguísticos, sociais e acadêmicos.

Ademais, temos percebido que, para alcançarmos a efetivação da Lei no 10.639/2003 e da Lei $\mathrm{n}^{\circ} 11.645 / 2008$, necessitamos começar pela problematização das relações étnico-raciais, sociais, culturais e pedagógicas existentes em nossa sociedade, pela formação de professores fundamentada em um exercício pedagógico capaz de promover o conhecimento e o reconhecimento da história, dos saberes e das formas de existência da população afro-brasileira, buscando eliminar as representações estereotipadas e folclóricas historicamente difundidas e alimentadas no chão da escola.

\section{Contribuição das Autoras}

Problematização e Conceituação: Neris C, Regis K, Muniz P e Sales T; Análise Formal: Neris C, Regis K, Muniz P e Sales T; Investigação: Neris C, Regis K, Muniz P e Sales T; Metodologia: Neris C, Regis K, Muniz P e Sales T; Escrita - Primeira Redação: Neris C, Regis K, Muniz P e Sales T; Escrita - Revisão e Edição: Neris C, Regis K, Muniz P e Sales T.

\section{Notas}

1. A Lei $\mathrm{n}^{\circ} 11.645$, de 10 de março de 2008 , altera a Lei $\mathrm{n}^{\circ}$ 9.394/96, anteriormente modificada pela Lei $\mathrm{n}^{\circ} 10.639 / 2003$, para incluir no currículo oficial da rede de ensino a obrigatoriedade da temática história e cultura afro-brasileira e indígena.

2. A respeito dos saberes construídos pelo movimento negro nas lutas por emancipação, consultar Gomes (2017).

3. Tendo em vista que a colonialidade permanece diretamente na manutenção de estruturas subjetivas, nos imaginários e na colonização epistemológica, a descolonização dos currículos é uma forma de promover condições e propostas para outros pensamentos, levantamento de práticas pedagógicas questionadoras e desafiadoras da voz única da modernidade ocidental e do poder colonial nela presente. São, portanto, currículos que incitam possibilidades de estar, ser, sentir, existir, fazer, pensar e saber de outro modo. Sobre esse tema, ver Walsh $(2010,2017)$.

4. Para Almeida (2020), o racismo, como processo histórico e político, cria as condições sociais para que, direta ou indiretamente, grupos racialmente identificados sejam discriminados de forma sistemática. Deve-se fazer "uma análise estrutural do racismo", já que a reprodução sistêmica de práticas racistas está na organização política, econômica e jurídica da sociedade.

5. Epistemicídio é uma das bases fundantes da colonização que atuam por meio da ideia de hierarquia e diferenciação entre as raças, promovendo a anulação e desqualificação dos conhecimentos dos povos subjugados mediante a lógica moderna e negando suas existências, saberes e vivências, num processo permanente de desqualificação. Dessa forma, o epistemicídio atende a uma lógica genocida da modernidade, massacrando povos e utilizando a racialidade enquanto baliza para hierarquizações, num processo persistente de produção da indigência cultural. A respeito do debate sobre epistemicídio, consultar Santos e Meneses (2009).

6. Sobre esse tema, consultar Quijano $(2007,2009)$. 
7. Colonialidade do ser e saber refere-se à forma como as diversidades humanas, suas existências e seus saberes foram encarados mediante o projeto de modernidade colonial, em que tais vivências foram negadas e seus epistemes suplantados ao negacionismo e ao desaparecimento. Dessa maneira, a colonialidade do saber e do ser manteve um processo de massacre de povos em suas diversidades de existências, saberes e fazeres. Sobre esse tema, ver Quijano $(2007,2009)$.

8. Pedagogia decolonial é uma prática pedagógica voltada para tornar visíveis outras formas de pensar e fazer-saber, para além do pensamento dominante. É uma prática pedagógica para a humanização voltada para um processo de intervenção-ação tanto no sentido de problematizar e desconstruir as práticas de saberes coloniais que permanecem vivazes em vários contextos da sociedade quanto de promover discussões para fomento de transformação para epistemes outras, novas práticas sociais e políticas. A esse respeito, consultar Walsh (2010, 2017).

9. Professores/as das escolas de educação básica que acompanham os/as residentes nas escolas-campo.

10. Docente do curso que orienta o estágio dos/as residentes estabelecendo a relação entre teoria e prática.

11. Esse trabalho de campo estava previsto para ocorrer em novembro de 2020. Entretanto, em decorrência da pandemia de Covid-19, foi adiado.

\section{Referências}

ADICHIE, C. O perigo de uma história única. Tradução de Julia Romeu. São Paulo: Companhia das Letras, 2019.

ALATAS, S. F. As definições e os tipos de discursos alternativos. Estudos Históricos, Rio de Janeiro, v. 23, n. 46, p. 225-245, dez. 2010. https://doi.org/10.1590/S0103-21862010000200001

ALMEIDA, S. Racismo estrutural. São Paulo: Sueli Carneiro; Jandaíra, 2020.

ANZALDÚA, G. Falando em línguas: uma carta para as mulheres escritoras do terceiro mundo. Estudos Feministas, Florianópolis, v. 8, n. 1, p. 229-236, 2000. https://doi.org/10.1590/\%25x

BRASIL. Lei no 9.394, de 20 de dezembro de 1996. Estabelece as Diretrizes e Bases da Educação Nacional. Diário Oficial da União, Brasília, Seção 1, p. 27.833, 23 dez. 1996.

BRASIL. Lei $n^{\circ} 10.639$, de 9 de janeiro de 2003. Altera a Lei $n^{\circ} 9.394$, de 20 de dezembro de 1996, que estabelece as Diretrizes e Bases da Educação Nacional, para incluir no currículo oficial da rede de ensino a obrigatoriedade da temática "História e Cultura Afro-Brasileira", e dá outras providências. Diário Oficial da União, Brasília, Seção 1, p. 1, 10 jan. 2003.

BRASIL. Diretrizes Curriculares Nacionais para a Educação das Relações Étnico-Raciais e para o Ensino de História e Cultura Afro-Brasileira e Africana. Brasília: MEC/Seppir, 2004.

BRASIL. Lei no 11.645, de 10 de março de 2008. Altera a Lei no 9.394, de 20 de dezembro de 1996, modificada pela Lei no 10.639, de 9 de janeiro de 2003, que estabelece as Diretrizes e Bases da Educação Nacional, para incluir no currículo oficial da rede de ensino a obrigatoriedade da temática "História e Cultura Afro-Brasileira e Indígena”. Diário Oficial da União, Brasília, Seção 1, p. 1, 10 mar. 2008.

BRASIL. Plano Nacional de Implementação das Diretrizes Curriculares Nacionais para a Educação das Relações Étnico-Raciais e para o Ensino de História e Cultura Afro-Brasileira e Africana. Brasília: Secad; Seppir, 2009. 
BRASIL. Diretrizes Curriculares Nacionais para a Educação Escolar Quilombola. Brasília: MEC/Secadi; SEB; CNE/CEB, 2012.

BRASIL. Portaria n 38, de 28 de fevereiro de 2018. Diário Oficial da União, Brasília, Seção 1, p. 28, $1^{\circ}$ mar. 2018. COELHO, W. N. B.; COELHO, M. C. As licenciaturas em História e a Lei 10.639/03 - percursos de formação para o trato com a diferença? Educação em Revista, v. 34, e192224, 2018. https://doi.org/10.1590/0102-4698192224

GARCÍA, J. C. Afroepistemología y pedagogía cimarrona. In: SEPTIEN, R. C. (org.). Afrodescendencias: voces en resistencia. En homenaje al centenario de Nelson Mandela. Ciudad Autónoma de Buenos Aires: Clacso, 2018. p. 59-70. Disponível em: http://biblioteca.clacso.edu.ar/clacso/se/20180712070816/ Afrodescendencias.pdf. Acesso em: $1^{\circ}$ abr. 2020.

GOMES, N. L. O movimento negro educador: saberes construídos nas lutas por emancipação. Petrópolis: Vozes, 2017.

GRUZINSKI, S. Os mundos misturados da monarquia católica e outras connected histories. Topoi, Rio de Janeiro, v. 2, n. 2, p. 175-195, mar. 2001. https://doi.org/10.1590/2237-101X002002007

GRUZINSKI, S. O historiador, o macaco e a centaura: a "história cultural" no Novo Milênio. Estudos Avançados, São Paulo, v. 17, n. 49, p. 321-342, 2003. https://doi.org/10.1590/S0103-40142003000300020

LANDER, E. Ciências sociais: saberes coloniais e eurocêntricos. In: LANDER, E. (org.). A colonialidade do saber: eurocentrismo e ciências sociais - perspectivas latino-americanas. Buenos Aires: Clacso, 2005. p. 8-23.

QUIJANO, A. Colonialidad del poder y clasificación social. In: CASTRO GÓMEZ, S.; GROSFOGUEL, R. (org.). El giro decolonial: reflexiones para una diversidad epistémica más allá del capitalismo global. Bogotá: Universidad Javeriana-Instituto Pensar, Universidad Central-Iesco, Siglo del Hombre, 2007. p. 285-327. Disponível em: http:// www.unsa.edu.ar/histocat/hamoderna/grosfoguelcastrogomez.pdf. Acesso em: 13 jul. 2021.

QUIJANO, A. Colonialidade do poder e classificação social. In: SANTOS, B. S.; MENESES, M. P. (org.). Epistemologias do Sul. Coimbra: Almedina, 2009. p. 119-131. Disponível em: http://www.mel.unir.br/ uploads/56565656/noticias/quijano-anibal\%20colonialidade\%20do\%20poder\%20e\%20classificacao\%20 social.pdf. Acesso em: 19 abr. 2021.

ROSA, M. C. A. África, o Sul e as ciências sociais brasileiras: descolonização e abertura. Sociedade e Estado, v. 30, n. 2, p. 313-321, maio/ago. 2015. https://doi.org/10.1590/S0102-699220150002000003

ROULLEAU-BERGER, L. The fabric of post-Western sociology: ecologies of knowledge beyond the "East" and the "West". Journal of Chinese Sociology, v. 8, n. 10, p. 1-26, 2021. https://doi.org/10.1186/s40711-021-00144-Z

SACRISTÁN, J. G. O currículo: uma reflexão sobre a prática. 3. ed. Porto Alegre: Artmed, 1998.

SACRISTÁN, J. G. O que significa o currículo? In: SACRISTÁN, J. G. Saberes e incertezas sobre o currículo. Porto Alegre: Penso, 2013. p. 16-35.

SANTOS, A. M. Vozes e silêncio do cotidiano escolar: análise das relações raciais entre alunos negros e não-negros em duas escolas públicas no município de Cáceres-MT. Dissertação (Mestrado) - Universidade Federal de Mato Grosso, Cuiabá, 2005. Dissertação. Disponível em: http://www.bdae.org.br/dspace/ bitstream/123456789/1676/1/tese.pdf. Acesso em: 20 jun. 2021 
SANTOS, B. S. Toward a new common sense: law, science and politics in the paradigmatic transition. Nova York: Routledge, 1995.

SANTOS, B. S.; MENESES, M. P. Introdução. In: SANTOS, B. S.; MENESES, M. P. (org.). Epistemologias do Sul. Coimbra: Almedina, 2009. p. 9-19.

UNIVERSIDADE FEDERAL DO MARANHÃO (UFMA). Resolução no 224. Maranhão: Consun, 2015. UNIVERSIDAde Federal do MARANHÃO (UFMA). Projeto Político-Pedagógico do Curso de Licenciatura Interdisciplinar em Estudos Africanos e Afro-Brasileiros. Maranhão: UFMA, 2017a.

UNIVERSIDADE FEDERAL DO MARANHÃO (UFMA). Resolução Consepe no $\mathbf{1 . 6 5 7}$, de 24 de outubro de 2017. Aprova a reformulação do Projeto Pedagógico do Curso de Licenciatura Interdisciplinar em Estudos Africanos e Afro-Brasileiros, modalidade presencial, no campus São Luís. Maranhão: UFMA, $2017 \mathrm{~b}$.

WALSH, C. Interculturalidad crítica y educación intercultural. In: VIANA, J.; TAPIA, L; WALSH, C. (org.). Construyendo interculturalidad crítica. La Paz: Instituto Internacional de Integración del Convenio Andrés Bello, 2010. p. 75-96. Disponível em: https://pt.slideshare.net/tiagovarges/construyendo-la-interculturalidadcrtica. Acesso em: 20 abr. 2021.

WALSH, C. Pedagogías decoloniales: praticas insurgentes de resistir, (re)existir y (re)vivir. Equador: AbyaYala, 2017. v. 1. (Serie Pensamento Decolonial).

\section{Sobre as autoras}

Cidinalva Silva Câmara Neris tem Licenciatura em História pela Universidade Federal do Maranhão (UFMA), mestrado em Ciências Sociais também pela UFMA e doutorado em Sociologia pela Universidade Federal de Sergipe, com estada de doutoramento no Institut des Sciences Sociales du Politique/École Normale Supérieure de Cachan, França. É professora adjunta da UFMA, atuando na Licenciatura Interdisciplinar em Estudos Africanos e Afro-Brasileiros. Tem interesse em pesquisas nas áreas: marcadores sociais da diferença e suas interseccionalidades: raça, classe, gênero e geração; sociologia das regulações jurídicas; sociologia do político e sociologia da família; mulheres; formação de professores para o ensino da história e da cultura africana e afro-brasileira; e currículo e política de ações afirmativas para ingresso no ensino superior. Atualmente coordena o Núcleo Interdisciplinar de Estudos Africanos e Afro-Brasileiros e integra a Associação Brasileira de Pesquisadores/as Negros/as e o Núcleo de Estudos Afro-Brasileiros/UFMA.

KÁtia Regis é graduada em História pela Universidade de São Paulo, mestre e doutora em Educação: Currículo pela Pontifícia Universidade Católica de São Paulo e pós-doutora pelo Programa de Pós-Graduação em Educação: Currículo da PUC-SP em parceria com o Departamento de História da Universidade Pedagógica de Moçambique. Atualmente, realiza na Universidade Púnguè (Moçambique) a pesquisa de pós-doutorado $A$ inclusão do conhecimento indígena nos currículos da África do Sul, de Moçambique, da Tanzânia e do Zimbabwe: possibilidades de fundamentos epistemológicos para o ensino da história e cultura afro-brasileira e africana, que possuifinanciamento da Fundação de Amparo à Pesquisa e ao Desenvolvimento Científico e Tecnológico do Maranhão. É professora associada II da Universidade Federal do Maranhão. Docente da Licenciatura Interdisciplinar em Estudos Africanos e Afro-Brasileiros, da qual foi coordenadora entre 2015 e 2020. Principais temas de discussão na área educacional: ensino da história e da cultura africana e afro-brasileira; currículo; formação de professores/as. 
Pollyanna Gouveia Mendonça Muniz possui graduação em História pela Universidade Federal do Maranhão (UFMA), mestrado e doutorado em História pela Universidade Federal Fluminense e pós-doutorado pela Universidade de Coimbra. É professora associada II na UFMA e professora do corpo permanente do Programa de Pós-Graduação em História também da UFMA (mestrado e doutorado). Atua na área de história colonial, religião e religiosidades e em teoria e metodologia da história. É membro do Núcleo Interdisciplinar de Estudos Africanos e Afro-Brasileiros e do Grupo de Pesquisa História, Religião e Cultura Material (UFMA).

Tatiane da Silva Sales é licenciada em História pela Universidade Estadual do Maranhão, mestre em História Social pela Universidade Federal da Bahia e doutora em História Social da Amazônia pela Universidade Federal do Pará. É professora adjunta na Universidade Federal do Maranhão, na Licenciatura Interdisciplinar em Estudos Africanos e Afro-Brasileiros. É membro e pesquisadora do Núcleo Interdisciplinar de Estudos Africanos e Afro-Brasileiros, vice-coordenadora do Grupo de Estudos e Pesquisa sobre Gênero e Sexualidade nas Práticas Educativas (UFMA) e atua/pesquisa nas áreas de história da educação feminina, discussões de gênero, sexualidade e relações étnico-raciais na história e na educação.

Recebido: 28 Jul 2021

Aceito: 28 Out 2021 